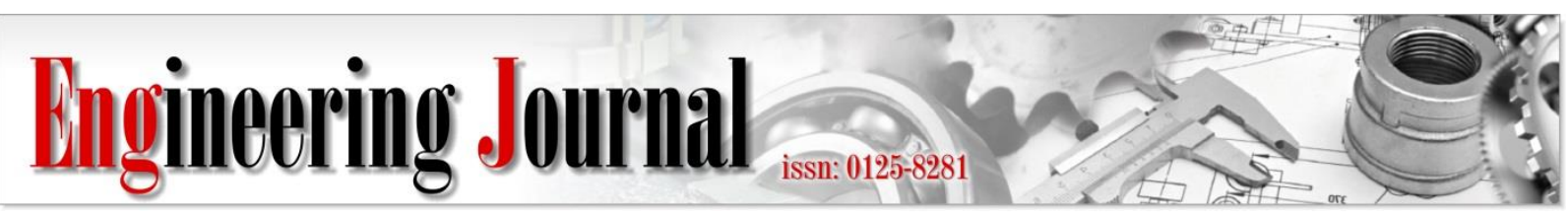

Article

\title{
Improvement of Thermal Distribution in the Rubber- Glove Former Conveyor Oven by OpenFOAM
}

\author{
Chakrit Suvanjumrat ${ }^{1,2, a, *}$ and Kittipos Loksupapaiboon ${ }^{1, b}$ \\ 1 Department of Mechanical Engineering, Faculty of Engineering, Mahidol University, Nakhon Pathom \\ 73170, Thailand \\ 2 Laboratory of Computer Mechanics for Design (LCMD), Department of Mechanical Engineering, Faculty \\ of Engineering, Mahidol University, Nakhon Pathom 73170, Thailand \\ E-mail: achakrit.suv@mahidol.ac.th (Corresponding author), bkittipos.lok@gmail.com
}

\begin{abstract}
The great number of rubber-glove formers was dried by the hot-air after dipping into the coagulant tank. The wet rubber-glove had been conveyed by chain into the oven with the producing speed and then the hot-air was blown to impinge the rubber-glove formers by the hot-air branch ducts which were installed under the conveyor chain paths. The traditional design of hot-air branch ducts was the cause which the rubber-glove formers were not achieved the hot-air thoroughly even though the grille of hot-air branch ducts was opened along the path of former motion. The computational fluid dynamics (CFD) had been applied to model and analyze the hot-air flow through the grille of the branch hot-air ducts inside the conveyor oven. The open source codes CFD software (OpenFOAM) was used to perform the computational technique to simulate the complex hot-air flow. The hotair branch ducts were improved to control the hot-air temperature distribution for the most uniformity regarding the CFD results. The temperature comparison between CFD and experiment at each point along the oven length was found that the CFD model confirmed an effective improvement and accuracy under an average error was less than $8.99 \%$.
\end{abstract}

Keywords: Conveyor oven, OpenFOAM, Reynolds averaged Naviers-Stokes equation (RANS) method, rubber glove, standard $k-\varepsilon$ model, thermal distribution.

ENGINEERING JOURNAL Volume 24 Issue 2

Received 2 October 2018

Accepted 17 February 2020

Published 31 March 2020

Online at https://engj.org/

DOI:10.4186/ej.2020.24.2.109 


\section{Introduction}

The conveyor oven has been used to bake product continuously. It is enormous then the inside temperature is difficult to control for a uniformity. In the rubber-glove producing process, the conveyor oven had been used to dry the coagulant and to vulcanize the latex film which coated hand shape formers. The manifold duct was designed to distribute the hot-air into the oven. The long rectangular air branch duct with many opening grilles usually installed under the rubber-glove formers which ran by the conveyor chain into the oven. The design of air distribution duct system was inapplicable; therefore, the hot-air did not flow through the duct and the heat did not distribute throughout the oven. The irregular vulcanization of rubber gloves was the severe problem which happened following the intermittent hot-air temperature inside the rubber-glove former oven. The lacking of theoretical supporting, the trial and error method was performed consistently to solve the unstable quality problem of the rubber glove manufacturing then it consumed the cost a lot and many times to set up the drying conditions of the oven.

Nowadays, the computational fluid dynamics (CFD) is referred to simulate the airflow to solve the intermittent temperature or to control the purpose temperature inside ovens. The CFD applications concerned food industries for design and analysis which were included of baking, drying, refrigeration and sterilization [1, 2]. The bread baking oven was the most simulation by using CFD methodology [3-5]. The other manufacturing apart from foods had been used CFD to analyze the temperature distribution inside the oven. The temperature distribution and the flow pattern in the paint curing oven for the metal parts of the air-condition production were improved using the CFD [6]. The temperature uniformity in the wire baking finish oven was investigated by decreasing the maximum temperature difference along the width of oven using CFD model [7]. The drying efficiency of the oven in the can making industry was increased by using the CFD simulation [8].

The turbulent flow happened inside oven and was governed by the $k-\varepsilon$ turbulence model [9-12]. The dimension of the industrial oven is large when compared with the branch ducts which are the hot-air distribution apparatus inside the oven. In order to create the oven model, many fine grids or cells had been employed to generate the CFD model. Consequently, the preparation and processing of CFD model were consumed many times to achieve the accuracy results. Many techniques were employed to reduce the complex parts inside the oven model. The 2-D simulation model was the simplest model for the symmetry or pattern oven geometry $[13,14]$. As a matter of fact, it was rare for the industrial oven of the rubber-glove producing process. The 3-D model has an effective simulation for the flow and thermal analysis within the industrial oven. The exceeding parts which were not affected to the turbulent flow were removed out of the 3-D simulation domain [15-17]. Unfortunately, some parts such as the hot-air duct are thin and small but it is important for the flow analysis; therefore, it cannot remove for the simplification model. The CFD simulations for the hot-air arrangements within the oven were widely performed using the commercial CFD software. It had the advantage technique to create the complex geometry domain but it had an expensive license cost [18]. Furthermore, some desirable CFD model could not be modified by user, and then the complex oven geometry was not simulated effectively.

In this research, the open source code CFD software (OpenFOAM) without license cost and allowing code modification which was validated the thermal convection flow with the physical experiment in our previous work [19] was applied to simulate the hot-air distribution for temperature uniformity inside the rubber-glove former oven. The CFD models of the rubber-glove former oven were developed to investigate the thermal distribution. The energy equation was written recently in the OpenFOAM code to calculate the hot-air flow. The thin wall of the hot-air branch duct was created and developed with the baffle equation to separate the internal and external flow domain inside the rubber-glove former oven model. The optimized technique of the hot-air branch duct distribution was proposed to improve the temperature uniformity of the rubber-glove former oven.

\section{Governing Equation}

The hot-air flow inside ovens is governed by the conservative equations which comprise the conservation of mass, momentum, and energy [20]. The governing equation of the mean flow is written by the following equations.

$$
\begin{aligned}
& \operatorname{div}\left(\bar{U}_{l}\right)=0 \\
& \frac{\partial \bar{U}_{l}}{\partial t}+\operatorname{div}\left(\bar{U}_{l} \bar{U}_{J}\right)=-\frac{1}{\bar{\rho}} \frac{\partial p}{\partial x_{i}}+\operatorname{div}\left(\operatorname{grad}\left(\bar{U}_{l}\right)\right) \\
& -\left(\frac{\partial\left(\overline{u^{\prime}{ }_{l} u_{J}}\right)}{\partial x_{i}}\right) \\
& \frac{\partial \bar{T}}{\partial t}+\operatorname{div}\left(\bar{T} \bar{U}_{l}\right)=\operatorname{div}\left(\frac{1}{\bar{\rho}}\left(\frac{\mu}{P_{r}}\right) \operatorname{grad}(\bar{T})\right) \\
& -\left(\frac{\partial\left(\overline{u_{l}^{\prime} T^{\prime}}\right)}{\partial x_{i}}\right)+\bar{S}_{T}
\end{aligned}
$$

where $\bar{U}_{l}$ is the time average velocity, $\bar{\rho}$ is the time average fluid density, $\mu$ is the fluid viscosity, $P_{r}$ is the turbulent Prandtl number, $\bar{S}_{T}$ is the source term, $-\overline{u^{\prime}{ }_{l} u^{\prime}}$ is the Reynolds stresses, $\bar{T}$ is the time average temperature, $\overline{T^{\prime}}$ is the time average temperature fluctuation.

The turbulent stresses are proportional to the mean velocity gradient or the mean rate of deformation which is written as follows:

$$
-\overline{u_{\imath}^{\prime} u_{j}^{\prime}}=\frac{2}{3} \delta_{i j} k-\frac{\mu_{t}}{\rho}\left(\frac{\partial U_{i}}{\partial x_{j}}+\frac{\partial U_{j}}{\partial x_{i}}\right)
$$

where $k$ is turbulent kinetic energy, $\delta_{i j}$ is the Kronecker delta $\left(\delta_{i j}=1\right.$ if $i=j$ and $\delta_{i j}=0$ if $\left.i \neq j\right), \rho$ is the fluid density, $\mu_{t}$ is the turbulence viscosity.

The turbulence viscosity is given by: 


$$
\mu_{t}=\rho C_{\mu} \frac{k^{2}}{\varepsilon}
$$

where $\varepsilon$ is the rate of turbulent kinetic energy dissipation per unit mass, $C_{\mu}$ is the dimensionless constant.

Because the inner structure of the rubber-glove former oven will be simplified, the $k-\varepsilon$ turbulence model is considered to present the properties of the hotair flow field. It can be written by the following equations.

$$
\begin{aligned}
\frac{\partial \rho k}{\partial t}+\operatorname{div}\left(\rho k \bar{U}_{l}\right)= & \operatorname{div}\left(\left(\frac{\mu_{t}}{\sigma_{k}}\right) \operatorname{grad}(k)\right) \\
& +2 \mu_{t} S_{i j} \cdot S_{i j}-\rho \varepsilon \\
\frac{\partial \rho \varepsilon}{\partial t}+\operatorname{div}\left(\rho \varepsilon \bar{U}_{l}\right)= & \operatorname{div}\left(\left(\frac{\mu_{t}}{\sigma_{\varepsilon}}\right) \operatorname{grad}(\varepsilon)\right) \\
& +C_{1} \frac{\varepsilon}{k} 2 \mu_{t} S_{i j} \cdot S_{i j} \\
& -C_{2} \rho \frac{\varepsilon^{2}}{k}
\end{aligned}
$$

where the velocity gradient yields:

$$
S_{i j}=\frac{1}{2}\left(\frac{\partial U_{i}}{\partial x_{j}}+\frac{\partial U_{j}}{\partial x_{i}}\right)
$$

The constant variables into the $k-\varepsilon$ model are described in Table 1.

Table 1. The constant variables of the $k-\varepsilon$ model.

\begin{tabular}{cccccc}
\hline $\begin{array}{c}\text { Constant } \\
\text { variable }\end{array}$ & $\boldsymbol{C}_{\boldsymbol{\mu}}$ & $\boldsymbol{\sigma}_{\boldsymbol{k}}$ & $\boldsymbol{\sigma}_{\boldsymbol{\varepsilon}}$ & $\boldsymbol{C}_{\mathbf{1}}$ & $\boldsymbol{C}_{\mathbf{2}}$ \\
\hline value & 0.09 & 1.00 & 1.30 & 1.44 & 1.92 \\
\hline
\end{tabular}

\section{The Rubber-Glove Former Oven}

The rubber-glove former oven is installed at the first step of rubber-glove producing process. The distance about one kilometer of the rubber-glove former movement by the conveyor chain is very long; therefore, the u-turn conveyor chain paths and oven layers have been designed for drying wet formers continuously. Figure 1 shows the oven for drying rubber-glove formers of the rubber-glove producing lines. The rubber-glove formers were moved following the arrow direction by the conveyor chain. This oven has three layers which were separated by the oven floor. Each oven layer has one entrance and one exit for the rubber-glove formers. A lot of formers are moved up the cleaning tank and run into the first oven layer successively. After moving out the first oven layer, the formers are moved in the coagulated tank and turned up to the second oven layer by a sprocket. The formers which are coated by the coagulant will be dried inside the second and third oven layer. The hot-air is blown by the centrifugal fan through the manifold duct to branch ducts entering the oven at its wall. The double wall was designed for the oven to insert the thermal insulation material. The first hot-air branch duct was connected to the wall of the first oven layer to blow the hot-air for drying the wet formers. The second and the third hot-air branch duct

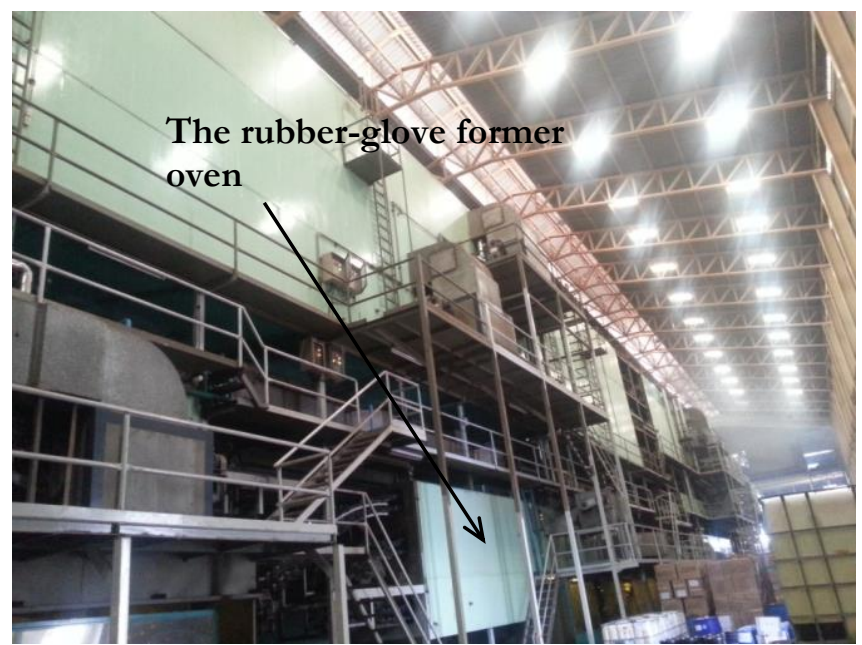

(a)

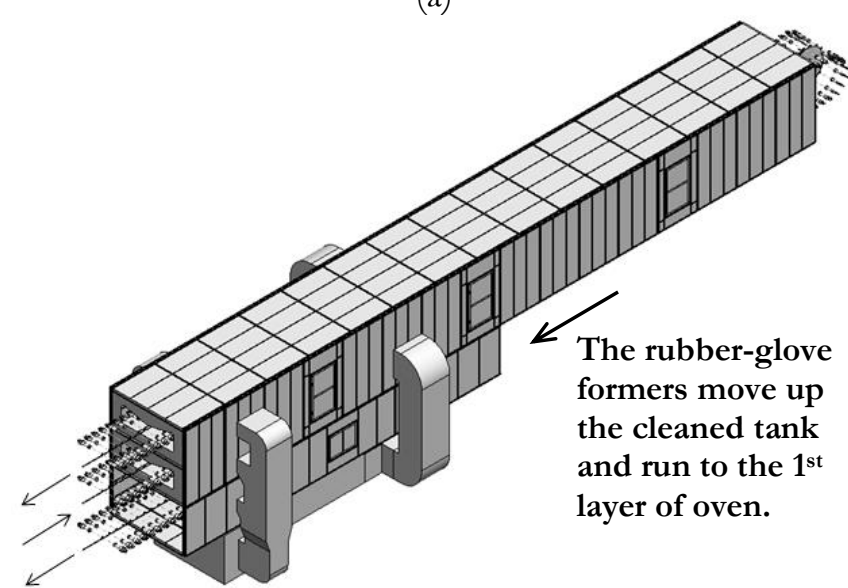

(b)

Fig. 1. The rubber-glove former oven: (a) installation in the rubber-glove processing line and (b) its 3-D model.

are passed thru the oven wall and laid on the oven floor along the rubber-glove former path inside the second and the third layer of oven, respectively. The top wall of hotair branch ducts is opened by many grilles for the hot-air distribution (Fig. 2). The returned air ducts were used with the hot-air distribution system. The returned air duct ends were installed on the second and third oven wall at the same level as the rubber-glove former path. Each oven layer had two hot-air inlets as the branch hot-air ducts and one hot-air outlet as the returned air duct. The hot-air manifold duct of the rubber-glove former oven had only one blower for distribution of hot-air with the constant air blowing velocity. The hot oil tubes were installed in front of the blower to blow the return air of the second and third oven past them into the branch air ducts.

The rubber-glove former oven which is carried out to improve the temperature uniformity is shown by drawing in Fig. 3. It has the total length, height and width of 18,000, 1,900 , and $2,158 \mathrm{~mm}$, respectively. The cross-section view showed the inside dimension of the $2^{\text {nd }}$ layer that was the height and width of 837 , and 2,004 mm, respectively. The cross-section of the $3^{\text {rd }}$ layer of the rubber-glove former oven had the height and width of 874, and 2,004 


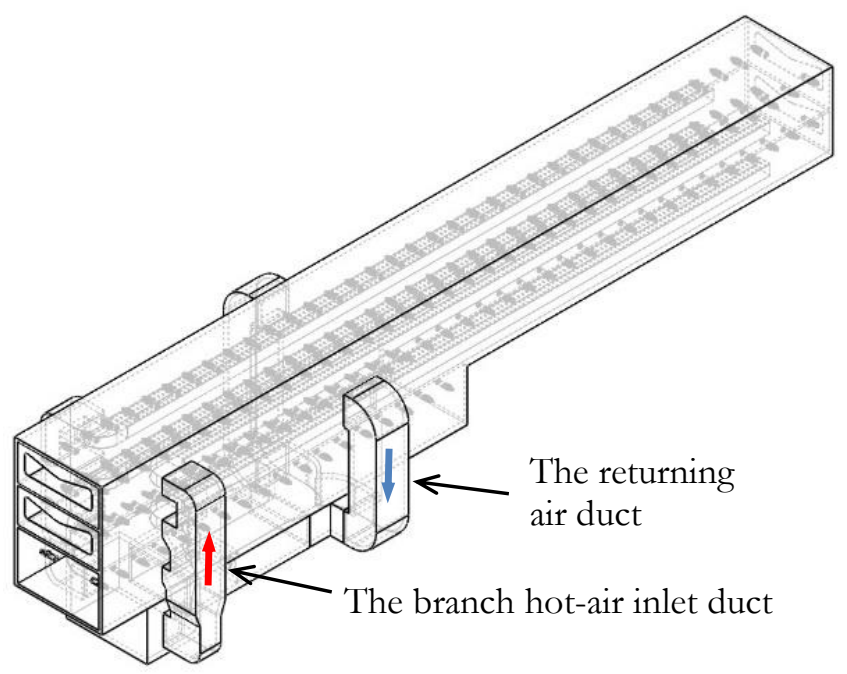

(a)

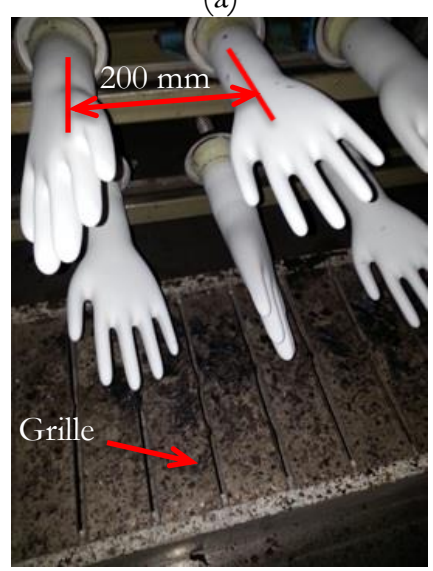

(b)

Fig. 2. (a) The 3-D model of branch air duct system of the rubber-glove former oven and (b) the grille on the top of branch air duct inside the rubber-glove former oven.

$\mathrm{mm}$, respectively. The oven which was used to dry coagulant on the rubber-glove formers was enormous to crate domain and improve by the CFD model.

\section{CFD Model Development}

The oven was separated into three layers; therefore, the second and the third layer of oven were separated to reduce the creation of enormous CFD domain for the flow simulation. The inlet and outlet duct which were attached to the outer wall of the rubber-glove oven were assumed by the hot-air inlet and outlet flow, respectively. The rubber-glove former paths were assumed to be the obstacle flow blocks which had dimensions same as the rubber-glove former and conveyor chain moving through the oven length. The hot-air branch ducts were modeled by the thin surface inside the oven. Two hot-air branch ducts with the grille on the top wall were modeled on the second and third oven layer floor. The return air channel was modeled on the oven wall by a rectangular hole. Each oven layer had been modeled the return air channel on the opposite side of oven wall.

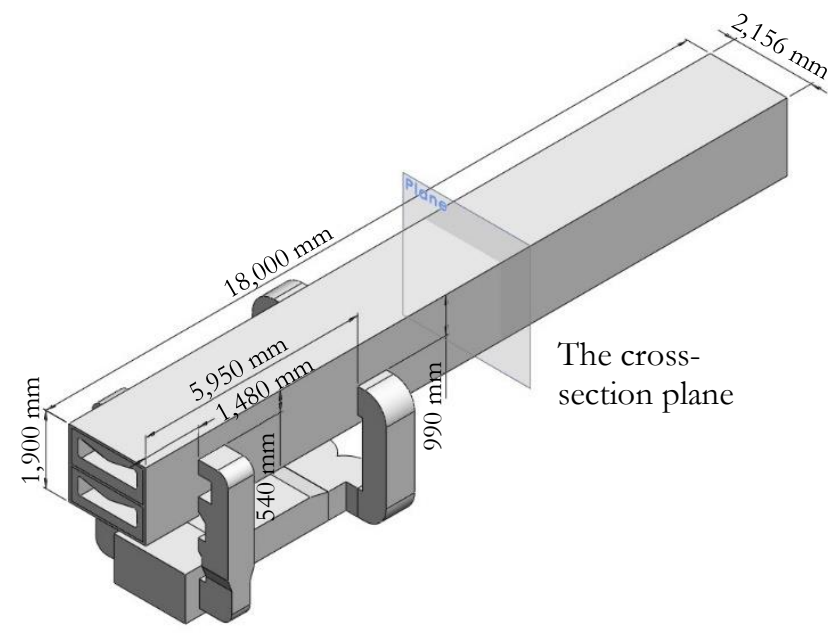

(a)

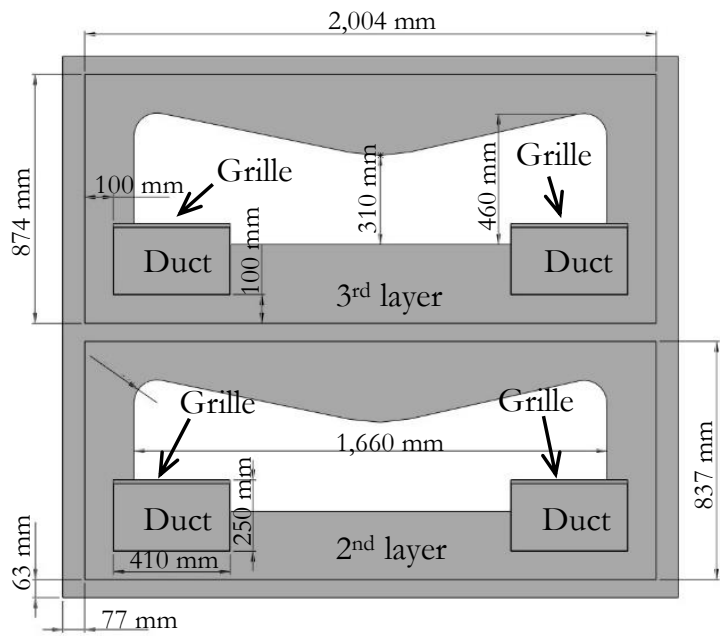

(b)

Fig. 3. The simplified model of: (a) the $2^{\text {nd }}$ and $3^{\text {rd }}$ oven layer, and (b) the cross-section of both layers of the rubber-glove former oven

The grille of physical branch duct had many little opening channels; therefore, many fine cells were required to create oven model for the simulation of hot-air flow through these channels. The fine cell reduction for the complex structure inside oven was challenged to the CFD domain creation. The Re of the hot-air flow through the grille between physical and CFD branch duct model was set up equally. The channel area of model was changed and wider than the physical grille, but it allowed the hotair flow as same velocity as the physical grille. Therefore, the fine cell decreasing could perform with the grille size of CFD model which was larger than the physical grille.

\subsection{Grid Generation}

The tetrahedron cells were used to create the CFD domain of the second and the third oven layers. Figure 4 shows the CFD model of the second and the third oven layers. The tetrahedron cells were used about 2,285,425 

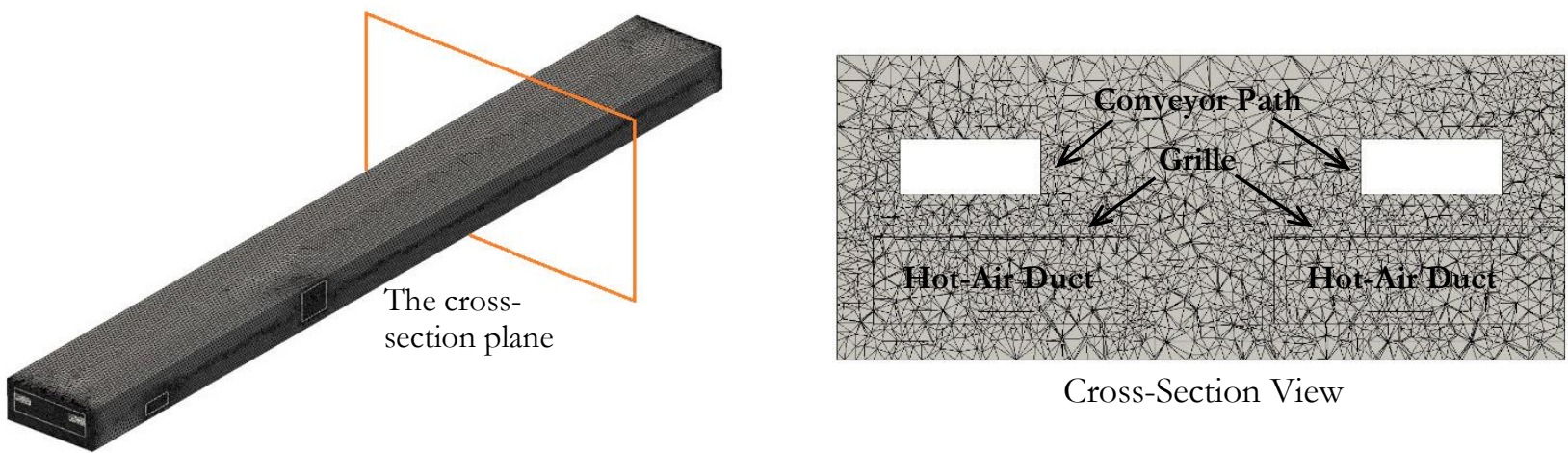

Cross-Section View

(a)
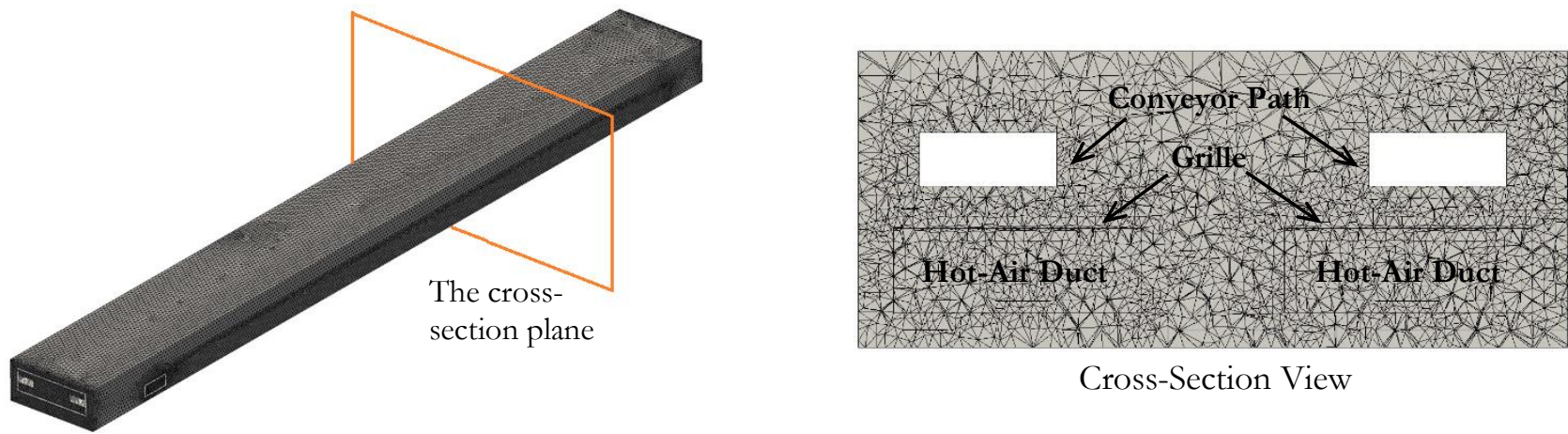

Cross-Section View

(b)

Fig. 4. The CFD model of: (a) the $2^{\text {nd }}$ and (b) $3^{\text {rd }}$ layer of the rubber-glove former oven with their section views.

and 2,271,425 cells for the second and the third oven layer models, respectively. Although the grille size was adjusted to simply generate cells, it remained to use the finest cells because of the very different dimension between grille and oven dimension. The finest cells would be created inside the hot-air distribution ducts. The first grid had a distance from the duct wall of $34.46 \mathrm{~mm}$ to conserve the laminar boundary condition. The cells were fined also near the internal wall of oven domains. The thin wall of branch duct including grille was not created directly. The surfaces of cell structure which was corresponded to the branch duct wall were generated inside the oven domain. This new cell generating technique could reduce cells of the CFD model well.

\subsection{Boundary Conditions}

The wall condition was defined on cell surfaces of the branch air duct wall by the zero gradient boundary condition. This boundary was used to control the entrance hot-air flow past the grille of hot-air branch duct. The thin wall of hot-air branch duct did not have to generate grids; therefore, it could reduce many cells of the rubber-glove former oven domain. The wall boundary equation can be written as follows:

$$
\frac{\partial \bar{U}_{i}}{\partial x_{i}}=0
$$

The hot-air temperature was measured by the thermocouple while its velocity was measured by the hot wire anemometer (Tenmars; model TM-4001). The hotair temperature was $140{ }^{\circ} \mathrm{C}$ which obtained by measuring at the inlet position of the physical rubber-glove former oven, was defined on the hot-air inlets of the oven model. The hot-air velocity was $7 \mathrm{~m} / \mathrm{s}$ also measured and defined on the inlets of oven. The outlet air of oven was measured and defined by the returned air with the constant velocity of $10 \mathrm{~m} / \mathrm{s}$. The entrance and exit of oven were defined the atmospheric pressure of $101.325 \mathrm{kPa}$. The environmental temperature of air which was defined at the entrance and exit of oven was $43^{\circ} \mathrm{C}$. The outer surface of oven domain except the entrance and exit was defined by the adiabatic boundary condition. This condition is written as follows:

$$
\frac{\partial \bar{T}}{\partial n_{i}}=0
$$

The inside surface of oven was defined the velocity effect by the no-slip boundary condition. It is written by the following equation.

$$
\bar{U}_{i}=0
$$

Figure 5 shows the descriptions of the boundary condition for the second and third layer of the rubberglove former oven model.

\subsection{Hot-Air Distribution Conditions}

In the normal operation, the grille of the branch duct is opened fully. In order to determine a suitable arrangement of grille opening, the grille was defined by the 

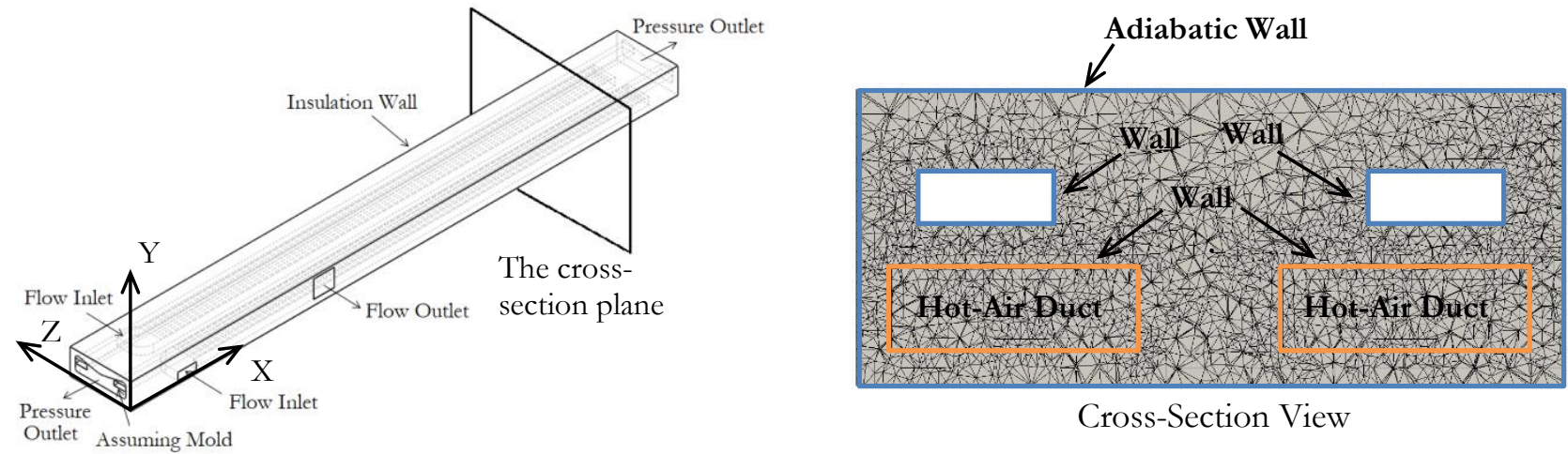

Cross-Section View

(a)
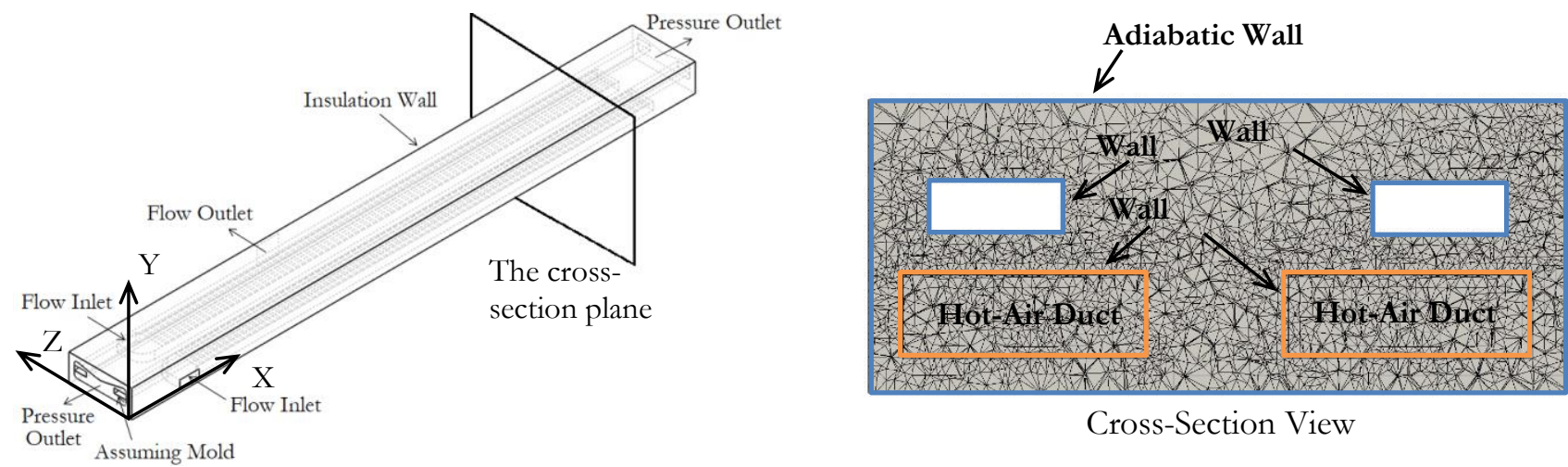

Cross-Section View

(b)

Fig. 5. The boundary conditions on the CFD model of: (a) the $2^{\text {nd }}$ and (b) $3^{\text {rd }}$ layer of the rubber-glove former oven with their section views.

five zones along the length of the hot-air distribution duct. Each zone was $20 \%$ of the total grille opening area for setting an opening zone. Figure 6 shows zones of the duct grille. The total length of the grille area was $14,600 \mathrm{~mm}$ then each zone had a length of $2,920 \mathrm{~mm}$. In order to improve the uniformity of temperature into the second and the third oven layers, the opening or closing zones would be selected to control the hot-air distribution. Table 2 and Table 3 describe the opening and closing zone for each case of the CFD simulation for the second and the third oven layers, respectively. The simulation cases were the total of 21 cases for determining of the suitable temperature uniformity inside the rubber-glove former oven.

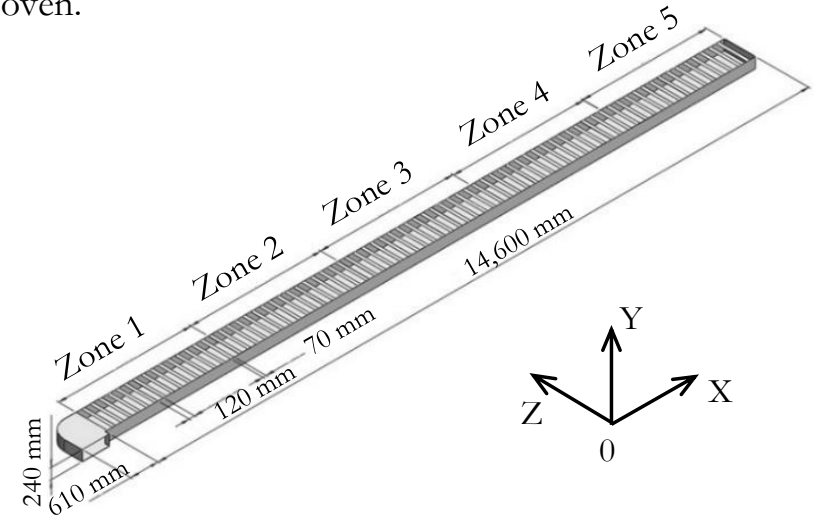

Fig. 6. The hot-air distribution zones of the air branch duct inside the rubber-glove former oven.
The steady state computation was assumed for the flow temperature and velocity inside the oven to simplify the problem. The SIMPLE algorithm and upwind differencing (UD) scheme were employed properly to determine the temperature and velocity of air flow inside the rubber-glove former oven. Ordinarily, the residuals were defined to be less than $10^{-3}$ at the end of the iteration. The CFD simulations were performed using a personal computer with Intel 1155 Corei5 $3.20 \mathrm{GHz} \mathrm{CPU}$ and 8 GB DDR2 SDRAM memory.

Table 2. The CFD simulation by the different duct grille operation of the $2^{\text {nd }}$ layer of oven.

\begin{tabular}{cccccc}
\hline Case & \multicolumn{5}{c}{ Distribution Zone } \\
\cline { 2 - 6 } No. & $\mathbf{1}$ & $\mathbf{2}$ & $\mathbf{3}$ & $\mathbf{4}$ & $\mathbf{5}$ \\
\hline 1 & $\otimes$ & $\otimes$ & $\otimes$ & $\otimes$ & $\otimes$ \\
2 & $\otimes$ & $\otimes$ & & $\otimes$ & \\
3 & $\otimes$ & $\otimes$ & & & $\otimes$ \\
4 & $\otimes$ & $\otimes$ & & $\otimes$ & $\otimes$ \\
5 & $\otimes$ & $\otimes$ & $\otimes$ & & $\otimes$ \\
6 & $\otimes$ & & $\otimes$ & $\otimes$ & $\otimes$ \\
7 & & $\otimes$ & $\otimes$ & & $\otimes$ \\
8 & & $\otimes$ & & $\otimes$ & $\otimes$ \\
\hline
\end{tabular}

The symbol, $\otimes$ is the opened zone. 
Table 3. The CFD simulation by the different duct grille operation of the $3^{\text {rd }}$ layer of oven.

\begin{tabular}{cccccc}
\hline Case & \multicolumn{5}{c}{ Distribution Zone } \\
\cline { 2 - 6 } No. & $\mathbf{1}$ & $\mathbf{2}$ & $\mathbf{3}$ & $\mathbf{4}$ & $\mathbf{5}$ \\
\hline 1 & $\otimes$ & $\otimes$ & $\otimes$ & $\otimes$ & $\otimes$ \\
2 & & & & & $\otimes$ \\
3 & & & & $\otimes$ & $\otimes$ \\
4 & & & $\otimes$ & $\otimes$ & $\otimes$ \\
5 & & $\otimes$ & $\otimes$ & $\otimes$ & $\otimes$ \\
6 & $\otimes$ & & $\otimes$ & $\otimes$ & $\otimes$ \\
7 & $\otimes$ & & $\otimes$ & & $\otimes$ \\
8 & $\otimes$ & & & $\otimes$ & $\otimes$ \\
9 & & $\otimes$ & $\otimes$ & $\otimes$ & \\
10 & $\otimes$ & $\otimes$ & $\otimes$ & $\otimes$ & \\
11 & $\otimes$ & $\otimes$ & $\otimes$ & & \\
12 & $\otimes$ & & $\otimes$ & $\otimes$ & \\
13 & & & $\otimes$ & $\otimes$ & \\
\hline
\end{tabular}

The symbol, $\otimes$ is the opened zone.

\section{Results and Discussions}

The simulation results of the CFD case were shown by the air temperature distribution and the streamline of air velocity inside the rubber-glove former oven.

\subsection{Simulation Results}

The rubber-glove former oven was operated by the full grille opening that means it was accorded to the case number 1 of the second and third oven layer simulation. In order to investigate the thermal distribution, the streamline and the hot-air temperature of the hot-air flow through the duct grills were illustrated. Figure 7 shows the streamline with hot-air velocity contour inside the second

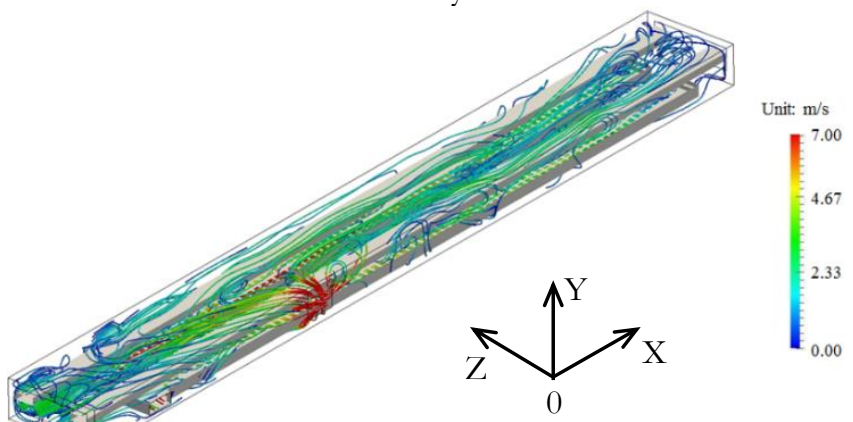

(a)

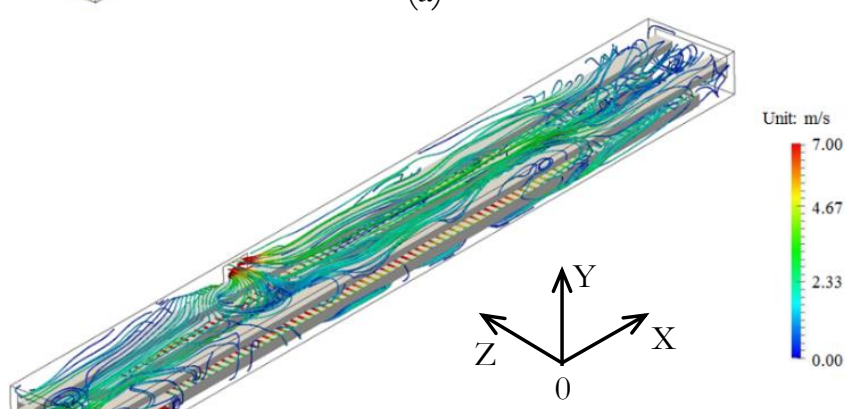

(b)

Fig. 7. The streamline inside (a) the $2^{\text {nd }}$ and (b) $3^{\text {rd }}$ layer of the rubber-glove former oven under the normal operation. and third layer of rubber-glove former oven while Fig. 8 shows the temperature distribution under the normal operation (case no. 1) of the rubber glove process. The color contour on stream line indicated the velocity value of hot-air flow. The maximum velocity was red while the minimum velocity was blue. The streamline showed the path of hot-air flow through the duct grille and out of the oven through the flow outlet. Consequently, the maximum hot-air temperature inside the second and third layers of the oven was trapped by the returned air duct to flow thoroughly the oven.

Figures 9 shows the cross-section view along the width $(\mathrm{x} / \mathrm{L}=0.36)$ at the returned air duct of second and third oven layer. The arrow expressed the hot-air flow direction. The color contour showed the impetuous velocity that the maximum velocity was red and the minimum velocity was blue. The hot-air was distinctly sucked out of the oven by the returned air duct. Therefore, the hot-air temperature which were obstructed by the sucked flow of the returned air duct could not be distributed to all oven zones. It was found that the maximum velocity which occurred at the outlet air of the returned air duct had a lot of effect to the uniform temperature distribution inside the oven. The hot-air temperature which was happened in the oven at zone number 3 to zone number 5 of the branch duct could not be transferred to the zone number 1 and 2 of both layers of oven. Moreover, the cold air at the exit of both layers was sucked inside the oven had very affected on the temperature deduction at zone number 1 and 2 . The CFD results represented the cause of the undistributed thermal in the rubber-glove former oven.

In order to analyze and develop the uniformity of the hot-air temperature, the average temperature along the

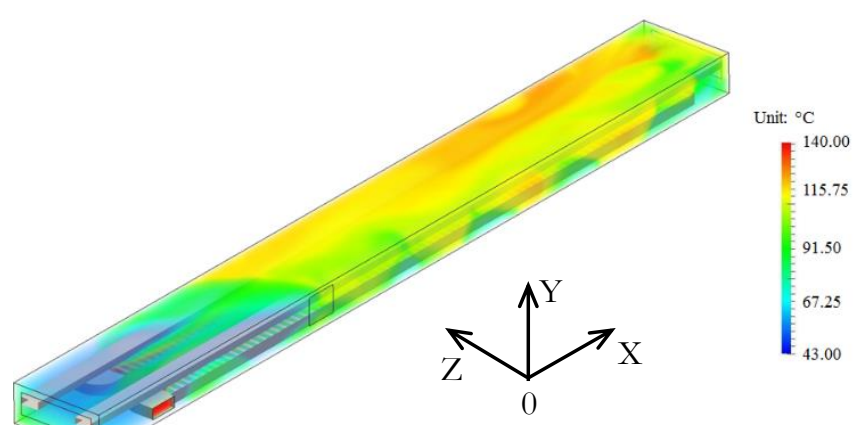

(a)

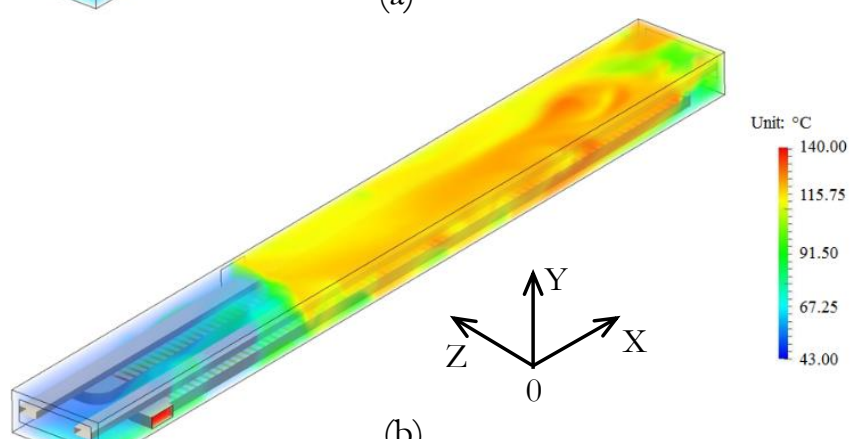

(b)

Fig. 8. The temperature distribution inside (a) the $2^{\text {nd }}$ and (b) $3^{\text {rd }}$ layer of the rubber-glove former oven under the normal operation. 


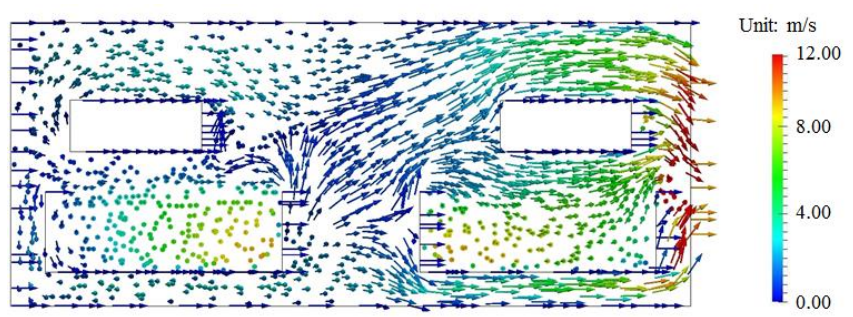

(a)

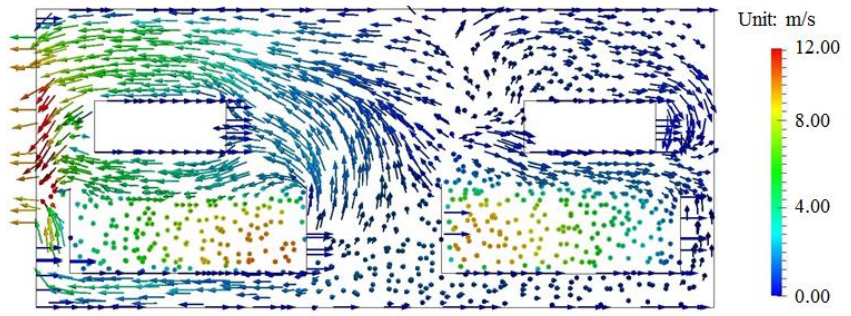

(b)

Fig. 9. The hot-air flow at the cross-section under the outlet flow of: (a) the $2^{\text {nd }}$ and (b) $3^{\text {rd }}$ layer of the rubberglove former oven.

length of oven was used to be the temperature reference. The temperature at $100{ }^{\circ} \mathrm{C}$ was desirable to dry the coagulant film on the rubber-glove formers. The temperature of all measurement points which was a low value of the standard deviation (SD) was implied the high hot-air temperature uniformity happening on that CFD case. The simulation result expressed that the suitable temperature uniformity happened at the case number 2 of the CFD results for the second oven layer. It had an average temperature of $100.48^{\circ} \mathrm{C}$ and the lowest standard deviation of $15.39{ }^{\circ} \mathrm{C}$. Subsequently, the simulation analysis showed that the suitable temperature uniformity happened at the case number 6 of the CFD results for the third oven layer. The average temperature and standard deviation of case number 6 was $104.70{ }^{\circ} \mathrm{C}$ and $13.74{ }^{\circ} \mathrm{C}$, respectively. Both $\mathrm{CFD}$ simulating cases were used to improve the opening zone of the air branch ducts inside the second and the third oven layers. In order to ensure of the improvement, the temperature at each point inside the oven was measured to compare with the CFD simulation results. The temperature at each point of the CFD and experimental result are plotted by graphs as shown in Fig. 12 for the second and the third layers of the rubber-glove former oven. It indicated that the CFD results had good agreement with the experimental results. The comparison of temperature measurement between CFD and experiment at the second layer oven had been found the average error of $7.36 \%$, while the third layer oven found an average error of $10.62 \%$.

The cool-air from the external environment had the most effect to drop the temperature near the measurement point number 1 and 2 . Consequently, the maximum temperature happened on the area inside the oven nearly the tip of the branch air ducts of the second and the third layer oven. This phenomenon was caused by the straight shape of air branch duct. It was the rectangular tube with the constant cross-section along the length of the oven. The cross-section which is reduced dimension from the entrance to the end will increase the pressure at the duct tip; therefore it will control the equal distribution of hotair through the air branch duct length. Nevertheless, the reduction of branch hot-air duct cross-section area can be effective to the uniformity of temperature inside the rubber-glove former oven, it was consumed the time and cost more than the improvement by the selection of opening and closing zone.

\subsection{Improvement and Validation}

The near wall temperatures inside the oven are measured using the K-type thermocouples (Fig. 10). The oven wall was drilled to prepare the installation holes for the thermocouple. It could be installed only on one side of oven wall because its opposite side was very closely to the oven of another rubber-glove producing line. There were no space for measuring the temperature by the $\mathrm{K}$ type thermocouples. Eight and nine points on wall of the second and third oven layer were drilled to insert the thermocouples for recording temperatures via thermocouple line by a data logger (Hioki; model LR843120). Figure 11 shows the positions which specified to measure the air temperature inside the second and the third oven layers under the stable condition. The temperature results of the CFD simulation regarding the measurement positions were analyzed the temperature uniformity. The average temperature and standard deviation of measuring temperatures were used to justify the temperature uniformity inside the oven. Table 4 and Table 5 show the average temperature and standard deviation of temperature for each case of the CFD simulation inside the second and the third layer ovens, respectively.

In order to analyze and develop the uniformity of the hot-air temperature, the average temperature along the length of the oven was used to be the temperature reference. The temperature at $100{ }^{\circ} \mathrm{C}$ was desirable to dry the coagulant film on the rubber-glove formers. The temperature of all measurement points which was a low value of the standard deviation (SD) was implied the high hot-air temperature uniformity happening on that CFD

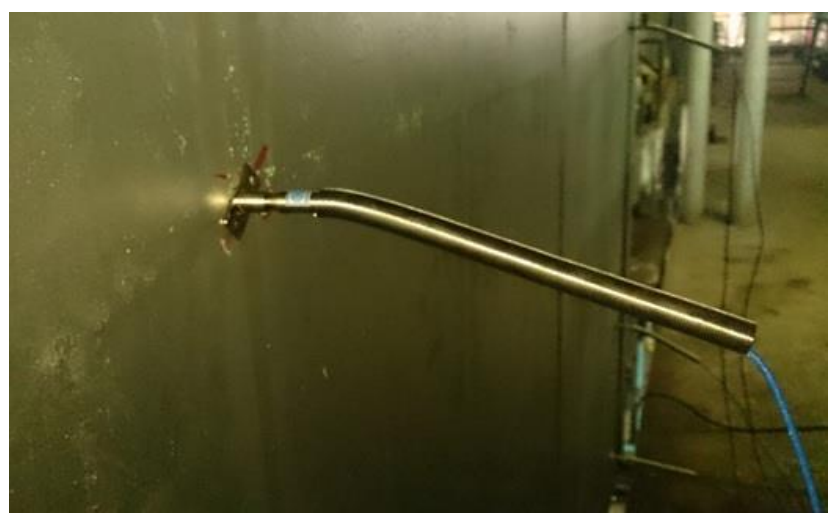

Fig. 10. The K-type thermocouple installation on the oven wall. 


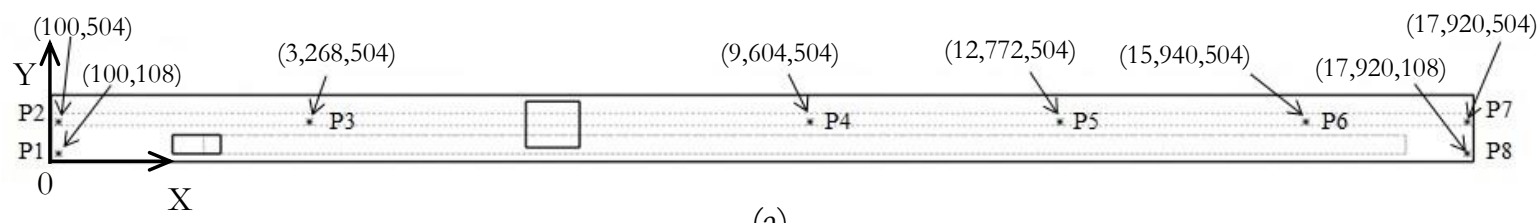

(a)

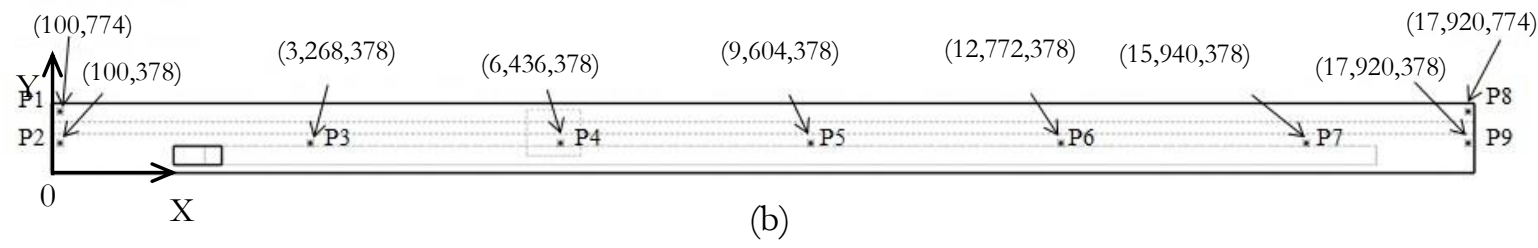

Fig. 11. The temperature measurement points by the K-type thermocouples on the oven wall of: (a) the $2^{\text {nd }}$ and (b) $3^{\text {rd }}$ layer.

Table 4. The CFD average error and standard deviation of air temperature in the $2^{\text {nd }}$ layer of the rubber-glove former oven.

\begin{tabular}{ccccccccc}
\hline \multirow{2}{*}{ Point } & \multicolumn{7}{c}{ Air Temperature of Simulation Case ( $\mathbf{C})$} \\
\cline { 2 - 9 } & $\mathbf{1}$ & $\mathbf{2}$ & $\mathbf{3}$ & $\mathbf{4}$ & $\mathbf{5}$ & $\mathbf{6}$ & $\mathbf{7}$ & $\mathbf{8}$ \\
\hline 1 & 52.07 & 66.88 & 54.50 & 53.85 & 56.26 & 62.66 & 43.00 & 43.00 \\
2 & 51.96 & 64.84 & 53.92 & 52.50 & 52.90 & 59.25 & 43.00 & 43.00 \\
3 & 64.20 & 72.71 & 56.65 & 59.55 & 62.64 & 61.02 & 43.00 & 43.00 \\
4 & 86.87 & 87.11 & 80.11 & 81.51 & 80.18 & 79.88 & 93.22 & 90.72 \\
5 & 109.84 & 110.03 & 116.54 & 112.92 & 110.56 & 114.01 & 118.55 & 115.23 \\
6 & 108.01 & 116.09 & 112.88 & 116.12 & 114.87 & 110.39 & 113.80 & 119.65 \\
7 & 113.51 & 119.29 & 63.62 & 114.18 & 118.61 & 115.61 & 127.04 & 125.31 \\
8 & 94.35 & 101.76 & 53.79 & 101.03 & 105.55 & 102.42 & 100.07 & 96.66 \\
9 & 89.59 & 96.34 & 44.57 & 91.36 & 94.85 & 91.08 & 98.41 & 97.85 \\
Avg. & 95.20 & 10.48 & 75.45 & 96.67 & 98.18 & 96.34 & 99.16 & 98.34 \\
SD & 15.93 & 15.39 & 26.80 & 19.29 & 18.90 & 18.76 & 25.52 & 25.61 \\
\hline
\end{tabular}

Table 5. The CFD average error and standard deviation of air temperature in the $3^{\text {rd }}$ layer of the rubber-glove former oven.

\begin{tabular}{|c|c|c|c|c|c|c|c|c|c|c|c|c|c|}
\hline \multirow{2}{*}{ Point } & \multicolumn{13}{|c|}{ Air Temperature of Simulation Case $\left({ }^{\circ} \mathrm{C}\right)$} \\
\hline & 1 & 2 & 3 & 4 & 5 & 6 & 7 & 8 & 9 & 10 & 11 & 12 & 13 \\
\hline 1 & 52.21 & 43.00 & 43.00 & 43.02 & 44.73 & 54.15 & 47.80 & 51.73 & 45.83 & 58.70 & 48.37 & 52.04 & 43.85 \\
\hline 2 & 55.91 & 43.00 & 43.00 & 43.07 & 47.31 & 60.00 & 54.23 & 53.45 & 43.39 & 63.88 & 52.96 & 57.85 & 45.62 \\
\hline 3 & 67.33 & 43.00 & 43.06 & 43.27 & 64.66 & 82.56 & 75.49 & 70.46 & 58.79 & 82.08 & 71.51 & 85.39 & 52.39 \\
\hline 4 & 93.08 & 80.14 & 116.0 & 109.2 & 97.98 & 89.61 & 83.51 & 93.63 & 95.56 & 87.81 & 122.3 & 93.74 & 108.2 \\
\hline 5 & 111.7 & 115.2 & 122.6 & 131.2 & 123.2 & 112.6 & 115.0 & 113.9 & 136.6 & 124.3 & 129.3 & 118.5 & 139.9 \\
\hline 6 & 119.4 & 116.2 & 138.5 & 139.4 & 133.1 & 117.7 & 119.4 & 114.4 & 137.2 & 130.3 & 69.19 & 129.7 & 138.8 \\
\hline 7 & 122.8 & 99.19 & 130.7 & 132.0 & 132.3 & 122.7 & 118.7 & 121.9 & 47.85 & 78.90 & 43.00 & 105.5 & 43.67 \\
\hline 8 & 107.2 & 99.18 & 107.1 & 103.7 & 109.9 & 108.5 & 119.5 & 111.6 & 48.29 & 78.03 & 43.00 & 83.87 & 43.40 \\
\hline 9 & 99.13 & 93.94 & 98.29 & 97.09 & 102.8 & 98.97 & 95.89 & 99.51 & 45.52 & 77.22 & 43.00 & 75.24 & 43.60 \\
\hline Avg. & 103.0 & 92.40 & 108.0 & 108.0 & 109.1 & 104.7 & 103.9 & 103.6 & 81.40 & 94.10 & 74.47 & 98.39 & 81.42 \\
\hline SD & 17.49 & 23.21 & 29.36 & 30.29 & 22.20 & 13.74 & 17.37 & 16.18 & 38.50 & 21.32 & 34.43 & 18.41 & 42.37 \\
\hline
\end{tabular}

case. The simulation result expressed that the suitable temperature uniformity happened at the case number 2 of the CFD results for the second oven layers. It had an average temperature of $100.48^{\circ} \mathrm{C}$ and the lowest standard deviation of $15.39{ }^{\circ} \mathrm{C}$. Subsequently, the simulation analysis showed that the suitable temperature uniformity happened at the case number 6 of the CFD results for the third oven layer. The average temperature and standard deviation of this case was $104.70{ }^{\circ} \mathrm{C}$ and $13.74{ }^{\circ} \mathrm{C}$, respectively. Both $\mathrm{CFD}$ simulation cases were used to improve the opening zone of the air branch ducts inside the second and the third oven layers. In order to ensure of the improvement, the temperature at each point inside the oven was measured to compare with the CFD simulation results. The temperature at each point of the CFD and experimental result are plotted by graphs as shown in Fig. 12 for the second and the third layers of the rubber-glove 


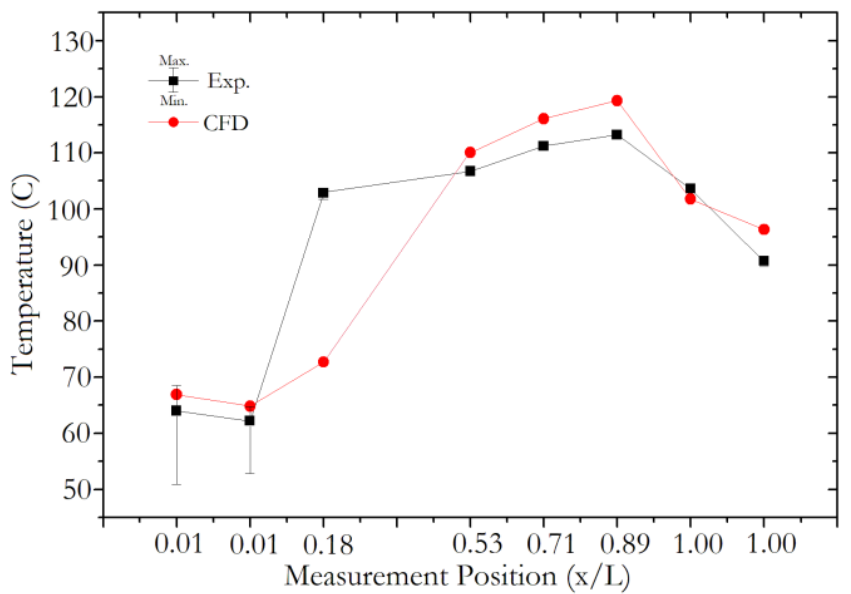

(a)

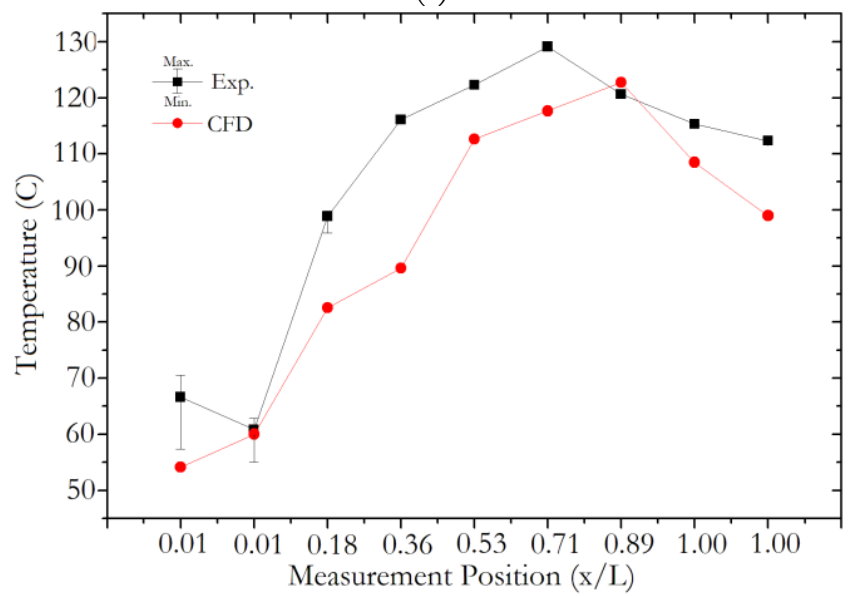

(b)

Fig. 12. The temperature at the measurement point of: (a) the $2^{\text {nd }}$ and (b) $3^{\text {rd }}$ layer of the rubber-glove former oven.

former oven. It indicated that the CFD results had good agreement with the experimental results. The comparison of temperature measurement between CFD and experiment at the second oven layers had been found the average error of $7.36 \%$, while the third oven layer found an average error of $10.62 \%$.

The cool-air from the external environment had the most effect to drop the temperature near the measurement point number 1 and 2. Consequently, the maximum temperature happened on the area inside the oven nearly the tip of the air branch ducts of the second and the third oven layers. This phenomenon was caused by the air branch duct shape was straight. It was the rectangular tube with the constant cross-section along the length of the oven. The cross-section which is reduced dimension from the entrance to the end will increase the pressure at the duct tip; therefore it will control the equal distribution of hot-air through the air branch duct length. Nevertheless, the reduction of cross-section area of hot-air branch duct can be effective to the uniformity of temperature inside the rubber-glove former oven, it was consumed the time and cost more than the improvement by the selection of opening and closing zones.

\section{Conclusions}

This research had been developed the CFD model of the rubber-glove former oven by the open source software (OpenFOAM) to improve the temperature uniformity. The CFD results can be explained behavior of the hot-air flow and thermal distribution inside the rubber-glove former oven as follows:

(a) The grille opening along the air branch duct under the path of conveyor chain is impossible to control the temperature uniformity inside the conveyor ovens such as the rubber-glove former oven.

(b) The CFD simulation revealed the effect of a position for installation of the returned air channel. It was found that the returned air channel should not be installed on the side wall of conveyor ovens which were installed the hot-air branch duct on its floor. The hot-air flow was sucked from the hot-air branch duct. Particularly, the strong outlet flow would suck the cold-air from the outside to inside of the oven past through the conveyor chain channel.

(c) The good thermal manipulation was found by the CFD analysis. The opening zone of the hot-air duct grille could be selected to arrange the temperature uniformity inside the rubber-glove former oven well. Particularly, it is the simple method which was performed immediately with the cheap price.

(d) The hot-air branch duct shape and position of the returned air channel should be improved in order to obtain the optimal temperature uniformity.

\section{Acknowledgement}

This research was funded by The Thailand Research Fund (TRF) and W. A. Rubbermate Co., Ltd under Research and Researchers for Industries (RRI) Master Scholarship (MSD58I0050). This work was also supported by the $60^{\text {th }}$ year supreme reign of His Majesty King Bhumibol Adulyadej Scholarship, granted by the faculty of graduate studies academic year 2014, Mahidol University.

\section{References}

[1] P. S. Mirade, J. D. Daudin, F. Ducept, G. Trystram, and J. Clement, "Characterization and CFD modelling of air temperature and velocity profiles in an industrial biscuit baking tunnel oven," Food Research Int., vol. 37, no. 10, pp. 1031-1039, Jul. 2004.

[2] M. Bohner, I. Barfuss, A. Heindel, and J. Muller, "Improvement the air flow distribution in a multibelt conveyor dryer for spice plants by modifications based on computational fluid dynamics," Biosystems Engineerings, vol. 115, no. 3, pp. 339-345, Jul. 2013.

[3] M. Pinelli and A. Suman, "Thermal and fluid dynamics analysis of an air-forced convection rotary bread-baking oven by means of an experimental and 
numerical approach," Appl. Therm. Eng., vol. 117, pp. 330-342, May 2017.

[4] U. Kokoji, L. Skerget, and J. Ravnik, "A numerical model of shortbread baking process in a forced convection oven," Appl. Therm. Eng., vol. 111, pp. 1304-1311, Jan. 2017.

[5] Z. Khatir, A. R. Taherkhani, J. Paton, H. Thompson, N. Kapur, and V. Toropov, "Energy thermal management in commercial bread-baking using a multi-objective optimization framework," Appl. Therm. Eng., vol. 80, pp. 141-149, Apr. 2015.

[6] S. Niamsuwan, P. Kittisupakorn, and A. Suwatthikul, "Enhancement of energy efficiency in a paint curing oven via CFD approach: case study in an airconditioning plant," Appl. Energ., vol. 156, pp. 465477, Oct. 2015.

[7] A. C. Ma, Y. Li, and H. L. Dong, "Optimized temperature uniformity and pressure loss in the baking finish oven of the enameled wire," Appl. Therm. Eng., vol. 78, pp. 670-681, Mar. 2015.

[8] S. Tanthadiloke, W. Chankerd, A. Suwatthikul, P. Lipikanjanakul, I. M. Mujtaba, and P. Kittisupakorn, "3D computational fluid dynamics study of a drying process in a can making industry," Appl. Therm. Eng., vol. 109, pp. 87-98, Oct. 2016.

[9] A. Chhanwal, A. Tank, K. S. M. S. Raghavarao, and C. Anandharamakrishnan, "Computational fluid dynamics (CFD) modeling for bread baking process-a review," Food Bioprocess. Technol., vol. 5, no. 4, pp. 1157-1172, May 2012.

[10] P. V. Morales, J. A. V. Castillo, R. R. Toledo, A. F. A. Alvarado, and J. M. P. Ortega, "Optimization and CFD modeling of an improved rustic oven for producing bricks," Clean Techn. Environ. Policy, vol. 18, no. 5, pp. 1599-1609, Jun. 2016.

[11] D. Kumlutus, O. Ozer, B. Eker, and I. D. Unsalan, "An aspirating cooling system for regulating temperature of pyrolytic oven gas," Appl. Therm. Eng., vol. 111, pp. 112-121, Jan. 2017.
[12] J. Wang, Y. Liu, B. Sunden, R. Yang, J. Baleta, and M. Vujanovic, "Analysis of slab heating characteristics in a reheating furnace," Energ. Convers. Manage., vol. 149, pp. 928-936, Oct. 2017.

[13] P. S. Mirade, "Prediction of the air velocity field in modern meat dryers using unsteady computational fluid dynamics (CFD) models," J. Food Eng., vol. 60, no. 1, pp. 41-48, Nov. 2003.

[14] N. Therdthai, W. Zhou, and T. Adamczak, "Twodimensional CFD modeling and simulation of an industrial continuous bread baking oven," J. Food Eng., vol. 60, no. 2, pp. 211-217, Nov. 2003.

[15] C. Suvanjumrat, "Comparison of turbulence models for flow past NACA0015 airfoil using OpenFOAM," Eng. J., vol. 21, no. 3, pp. 207-221, Jun. 2017.

[16] E. Chaichanasiri and C. Suvanjumrat, "The $k-\varepsilon$ turbulence model to simulate the two-phase flows of fluid in flumes using $\mathrm{C}++$ open source computational fluid dynamic software," Kasetsart J. (Nat. Sci.), vol. 47, pp. 460-477, Mar. 2013.

[17] E. Chaichanasiri and C. suvanjumrat, "Simulation of three dimensional liquid-sloshing models using open source code CFD software," Kasetsart J. (Nat. Sci.), vol. 46, pp. 978-995, Oct. 2012.

[18] T. Norton, and D. W. Sun, "Computational fluid dynamics (CFD)-an effective and efficient design and analysis tool for the food industry: a review," Trends Food Sci. Tech., vol. 17, no. 11, pp. 600-620, Nov. 2006.

[19] C. Suvanjumrat, "Implementation and validation of OpenFOAM for thermal convection of airflow," Eng. J., vol. 21, no. 5, pp. 225-241, Sep. 2017.

[20] H. K. Versteeg, and W. Malalasekera, "Turbulence and its modelling," in An Introduction to Computational Fluid Dynamics-the Finite Volume Method, 2nd ed. London, England: Pearson Education Limited, 2007, ch. 3, pp. 40-114. 


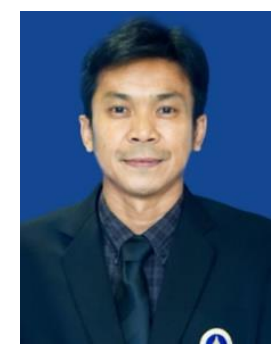

Chakrit Suvanjumrat was born in Nakhon Si Thammarat, Thailand, in 1973. He received the Bechelor's degrees in mechanical engineering from Prince of Songkla University, Songkhla, Thailand, in 1995. He received the Master's and Doctor's degree in mechanical engineering from Kasetsart University, Bangkok, Thailand, in 2003 and 2009, respectively.

$\mathrm{He}$ is curently an associate professor at department of mechanical engineering, faculty of engineering, Mahidol University, Nakhon Pathom, Thailand. He is head of Laboratory of Computer Mechanics for Design (LCMD) under mechanical engineering, faculty of engineering, Mahidol University, Nakhon Pathom, Thailand.

His research interests focus on CAD/CAE, Finite Element Analysis (FEA), CFD, Fluid-Structure Interaction (FSI) and product design.

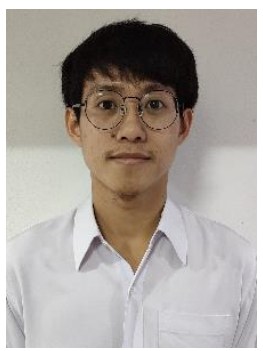

Kittipos Loksupapaiboon was born in Yala, Thailand, in 1991. He received the first class hornor for Bechelor's degrees in mechanical engineering from Mahidol University, Nakhon Pathom, Thailand, in 2013. He received the Master's degree in mechanical engineering from Mahidol University, Nakhon Pathom, Thailand, in 2017.

$\mathrm{He}$ is working toward the $\mathrm{PhD}$ in Mechanical Engineering from Mahidol University. He recives the supporting found by the Research and Researchers for Industries (RRI) PhD Scholarship grant no. PHD61I0003 under the Thailand Research Fund (TRF).

His research interests focus on CFD, OpenFOAM software and heat transfer. 